\title{
Investigation on the Influence of Water-Shale Interaction on Stress Sensitivity of Organic-Rich Shale
}

\author{
Xiangjun Liu $\mathbb{D}$, Yan Zhuang $\mathbb{D}$, Lixi Liang, and Jian Xiong $\mathbb{D}$ \\ State Key Laboratory of Oil and Gas Reservoir Geology and Exploitation, Southwest Petroleum University, Chengdu, \\ 610500 Sichuan, China \\ Correspondence should be addressed to Yan Zhuang; zhuangy1991@163.com
}

Received 6 May 2019; Revised 16 July 2019; Accepted 22 August 2019; Published 7 October 2019

Academic Editor: Mohammad Sarmadivaleh

Copyright $\odot 2019$ Xiangjun Liu et al. This is an open access article distributed under the Creative Commons Attribution License, which permits unrestricted use, distribution, and reproduction in any medium, provided the original work is properly cited.

\begin{abstract}
Shale reservoirs are characterized by low permeability and natural fractures. In the process of reservoir development, the working fluid enters the reservoir. This may result in the formation of new fractures or expansion of natural fractures. When shale reservoirs are exploited, the fluid pressure in the fracture or pore is reduced. This destroys the stress balance of the reservoir, produces stress sensitivity damage, and reduces the reservoir permeability. Organic-rich shale from the Yanchang Formation, Chang 7 Member of the Ordos Basin, was selected for core flow experiment with helium. The effects of the type of brine, salinity, and soaking time on the stress sensitivity of an organic-rich shale reservoir were investigated. The acoustic characteristics were also investigated to study the effect of interactions between water and shale on stress sensitivity. The experimental results demonstrate that the interactions of water and shale increase the permeability of shale and reduce its stress sensitivity. Furthermore, when the permeability of the shale is excessively low, the stress sensitivity is high. In the acoustic studies, a higher attenuation coefficient of the acoustic wave corresponds to a larger variation in the shale structure and thus a larger permeability of the shale and smaller stress sensitivity coefficient. Whereas there is no apparent effect of the salt water type on the stress sensitivity, higher salinity levels cause higher stress sensitivity. After reacting with $15000 \mathrm{mg} / \mathrm{L}$ brine, the stress sensitivity coefficient of shale did not decrease significantly compared with that before action, all of which were above 0.97 . However, after reacting with distilled water or $5000 \mathrm{mg} / \mathrm{L}$ brine, the stress sensitivity coefficient of shale decreased significantly, and all of them decreased to less than 0.9. Longer water exposures, corresponding to an increased duration of water-shale interactions, result in higher impacts on the stress sensitivity of shale. After 6 hours of shale-brine interaction, the stress sensitivity coefficient of shale is as high as 0.93 , while after 48 hours of shale-brine interaction, the stress sensitivity coefficient of shale is reduced to 0.88 . This study provides a highly effective reference with regard to the influence of the working fluid on the reservoir during drilling operations and the study of reservoir characteristics after fracturing.
\end{abstract}

\section{Introduction}

Shale gas, an unconventional oil resource, is attracting increasing attention owing to the increasing demand for oil and natural gas with the rapid development of the global economy [1-4]. There are abundant shale gas resources worldwide, mainly distributed in China, the United States, Argentina, Mexico, and South Africa. Of these countries, the United States has the most successful shale industry. The development of shale gas in China is encountering enormous challenges because the reservoirs here are different from those in the United States [5, 6].
The permeability of organic-rich shale is very low, notwithstanding the presence of well-developed microfractures. In the process of exploitation, a decrease in the pore pressure may cause reservoir compression and reduce the reservoir permeability further. Thus, hydraulic fracturing is required for the development of shale gas resources. Fractures generated after shale fracturing may enlarge seepage channels and the permeability of reservoirs. However, they may also cause strong stress sensitivity damage to the reservoirs [7-10]. In addition, in the drilling process, the working fluid may enter the reservoir. This can result in a reaction between the water and rock. In similar processes, the formation of 
new cracks or further expansion of the original cracks causes stress sensitivity damage to the reservoir. Therefore, an investigation of the stress sensitivity of shale reservoirs is of substantial value for the efficient development of reservoirs.

Many scholars [11-16] have studied the relationship between the permeability and stress of conventional oil and gas reservoirs and have obtained remarkable results. $\mathrm{Wu}$ et al. [17] studied the factors influencing the stress sensitivity of shale by considering the overlying formation pressure. They concluded that shale exhibits strong stress sensitivity. They also determined that the mineral composition and mechanical properties of rocks affect the stress sensitivity directly. In addition, Zhang et al. [18] investigated the stress sensitivity of shale from the perspective of rock dynamics and a reservoir's physical properties. They observed that the nanoscale lamellar pores of shale exhibit strong stress sensitivity. What is more, some scholars do the research about the reason why shale exhibits strong stress sensitivity. For example, He et al. [19] performed several experiments and concluded that the stress sensitivity of rocks is affected mainly by the composition and type of cements. The factors that can affect the stress sensitivity of shale were also investigated by some scholars. Liu et al. [16] proposed a zero-stress model that is applicable after the failure of the elastic fracture model. Wang et al. [20] investigated the velocity sensitivity of a lignite reservoir under different stresses through the orthogonal experiments. This provides a new method for the corresponding research. The effects of the main factors, including the $\mathrm{pH}$, salinity, and effective stress, on each index were analyzed. In addition, Zhao et al. and Pervukhina et al. $[21,22]$ studied the effects of different factors on the stress sensitivity and established a corresponding model. However, the interactions of water and shale were not considered. What is more, Xiao et al. [8] indicated that the key factor in rock stress sensitivity is whether a fracture develops or not. They also observed that the rocks formed of illite or mixed mineral exhibit stronger stress sensitivity. This corroborates Wu's research results. Furthermore, in Zhang et al.'s work [23], the porosity sensitivity exponent and pore compressibility were determined based on a dual-porosity model. The authors of that work postulate that the pore compressibility is the dominant factor influencing the stress sensitivity.

The importance of stress sensitivity studies is evident. The interaction of water and shale is an important cause of the instability in the walls of a well while developing shale gas. Many scholars [20, 24-26] have researched the interactions of water and shale. From the production point of view, water-rock interaction is conducive to enhancing oil recovery. Gao et al. [27] studied the inhibition characteristics of shale and hypothesized that the interactions of water and the clay minerals result in fractures, which aid in improving reservoir recovery. While the water-rock interaction has a great influence on reservoirs, some scholars investigated the influence of water-rock interaction on reservoirs. You et al. and Kang et al. [28-30] investigated the influence of fluid intrusion, such as that by the fracturing fluid, on shale stress sensitivity from the perspective of reservoir damage. They indicated that the physicochemical action of the fracturing fluid weakens the shale fracture surface mechanics. This facilitates the compression and closure of shale microfractures and thus strengthens the stress sensitivity of shale. They also observed that the effective support of a proppant can weaken the shale stress sensitivity. In addition, Liu et al. [31] investigated the interaction mechanisms of water and organic-rich shale in the Longmaxi Formation from a microcosmic perspective. Holt and Kolstø [32] systematically analyzed the effects of water contact with clay minerals on the properties of shale. They observed that the micro-/nanopores of hard and brittle shale strengthened the effect of the waterrock reaction. Moreover, Qian et al. [33] used NMR and CT scans to carry out experiments on the interactions of water and shale. They indicated that the interactions of water and shale cause new fractures in the reservoir, thereby increasing the complexity and connectivity of the reservoir fracture network and thus the permeability of the reservoir. In addition, Davudov and Moghanloo [34] also studied the effect of shale pore connectivity on permeability. They theorized that an increase in the effective pressure would reduce the permeability of shale owing to the closure of microfractures, resulting in lower connectivity. These studies demonstrate that the interactions between water and shale play an important role in stress sensitivity. However, the stress sensitivity of reservoirs after the exposure of shale to water is yet to be studied.

Although various scholars have investigated the stress sensitivity of shale, previous studies were mostly intuitive analyses of the experimental results, rock mineral composition, and rock mechanical properties. Multiple factors have rarely been analyzed simultaneously. Furthermore, none of these studies consider the effects of the interactions between water and shale on the stress sensitivity of organic-rich shale. In this work, we consider the organic-rich shale of the continental Yanchang Formation the sample and study the effects of the interactions between water and shale on the stress sensitivity in organic-rich shale. We do so by considering three aspects: brine type, salinity, and soaking time. The influence of the water-rock interactions on the internal structure of shale can be assessed by the variation in the initial permeability. It can be established also by the experimental results of acoustic wave characteristics.

\section{Experimental Procedures}

There are two main types of stress sensitivity experiments [35-38]: constant flow pressure changing confining pressure and constant confining pressure changing flow pressure. In the former, when the difference between the overburden rock pressure and pore fluid pressure is constant, a decrease (increase) in the pore fluid pressure can be regarded as an increase (decrease) in the overburden rock pressure. That is, the effect of increasing the confining pressure and reducing the flow pressure on stress is approximately identical. This method is used by most scholars owing to its simplicity. However, the latter (constant confining pressure) requires relatively high performance of the experimental instruments. Moreover, it simulates the real stress situation of reservoir rocks in the process of oil and gas exploitation. However, the experimental process is more complex, and it is inconvenient to ensure a stable internal pressure. Because the 
experimental error caused by the research process is large, so only a few scholars have used this method to study the stress sensitivity of reservoirs. The method of constant flow pressure, changing confining pressure, is used in this study. Many experts have evaluated the stress sensitivity using exponential or power law forms. This study mainly adopts the stress sensitivity index method proposed by Li. It is highly accurate and is widely used $[39,40]$.

In this study, the effects of water on the stress sensitivity of shale were investigated by controlling the type of brine, the concentration of brine, and the soaking time. Core flow experiments were used to determine the stress sensitivity by fixing the flow pressure and measuring the permeability changes by controlling the confining pressure (increasing it first and then decreasing it). The pressures used in this experiment were $2.5,5.0,10.0,15.0$, and $20.0 \mathrm{MPa}$. All the plunger cores of the experiment measured the stress sensitivity with helium. Furthermore, scanning electron microscopy and acoustic testing were used to explain the effects of the interactions between water and shale on the stress sensitivity.

The equation for calculating the acoustic attenuation coefficient $\alpha$ of the rock samples (unit: $\mathrm{Db} / \mathrm{m}$ ) is

$$
\alpha=\frac{\ln A_{0}-\ln A}{L}
$$

where $\alpha$ is the acoustic attenuation coefficient of the rock samples (unit: $\mathrm{Db} / \mathrm{m}$ ), $A_{0}$ is the first wave amplitude of the probe docking (unit: volt), $A$ is the first wave amplitude of the rock samples (unit: volt), and $L$ is the length of the rock samples (unit: $\mathrm{m}$ ).

2.1. Samples. The fundamental physical properties of hard and brittle shales vary substantially across different areas. We obtained the experimental samples from the Yanchang Formation organic-rich shales and tested the stress sensitivity of the samples with a HKGP-3 permeability and porosity tester for compact cores. The organic-rich shale of the Yanchang Formation is black shale with an average porosity of $1.3 \%$ and a permeability of $1.56 \times 10^{-2} \mathrm{mD}$. In order to understand the fundamental characteristics of the experimental cores further, whole rock analysis and scanning electron microscopy experiments were carried out on the cores.

The cores used for the experiments were mainly plunger cores. Their fundamental parameters are listed in Table 1.

Table 1 reveals that the core used in the experiment is a standard core $(L \times D \approx 5.0 \times 2.5)$. It exhibits low porosity and low permeability. Furthermore, the results can be compared because the fundamental parameters of the different cores are relatively similar.

\subsection{Stress Sensitivity Experiment}

2.2.1. Stress Sensitivity Experiments of Shale with Different Brine Types. It is established that different types of brine react differently with shale. The purpose of this experiment was to study the effects of the saltwater type on the stress sensitivity of shale. In accordance with previous studies $[29,31,41]$, the reaction time of water and shale was set to $48 \mathrm{~h}$. In order to prevent the formation of new cracks during the drying
TABLE 1: Fundamental parameters of experimental cores.

\begin{tabular}{lccccc}
\hline Number & $\begin{array}{c}\text { Length } \\
(\mathrm{cm})\end{array}$ & $\begin{array}{c}\text { Diameter } \\
(\mathrm{cm})\end{array}$ & $\begin{array}{c}\text { Weight } \\
(\mathrm{g})\end{array}$ & $\begin{array}{c}\text { Porosity } \\
(\%)\end{array}$ & $\begin{array}{c}\text { Permeability } \\
(\mathrm{md})\end{array}$ \\
\hline 1 & 5.01 & 2.55 & 61.68 & 2.0 & $2.128 E-02$ \\
2 & 5.03 & 2.54 & 61.45 & 2.1 & $2.180 E-02$ \\
3 & 5.01 & 2.54 & 61.58 & 1.3 & $2.304 E-02$ \\
4 & 5.02 & 2.54 & 61.15 & 1.3 & $3.342 E-02$ \\
5 & 4.99 & 2.54 & 61.72 & 0.2 & $2.326 E-02$ \\
6 & 5.01 & 2.53 & 61.49 & 1.3 & $1.962 E-02$ \\
\hline
\end{tabular}

process, low-temperature drying $\left(60^{\circ} \mathrm{C}\right)$ was adopted in this experiment. The specific steps of this experiment are as follows:

(1) Three brine types were prepared: distilled water, a $5000 \mathrm{mg} / \mathrm{L} \mathrm{NaCl}$ solution, and a $5000 \mathrm{mg} / \mathrm{L} \mathrm{KCl}$ solution

(2) Cores 1, 2, and 3 were immersed in distilled water, the $\mathrm{KCl}$ brine, and the $\mathrm{NaCl}$ brine, respectively, for $48 \mathrm{~h}$. This was performed so that the shale and fluid could interact completely

(3) After the reaction was complete, the cores were removed and placed in a thermostat. The temperature was set to $60^{\circ} \mathrm{C}$, and the cores were dried for $48 \mathrm{~h}$

(4) Sound wave tests were carried out on cores 1, 2, and 3 after the drying

(5) Finally, the cores were tested for stress sensitivity

(6) The results of the experiment were compared with those of the original rock

2.2.2. Stress Sensitivity Experiments of Shale with Different Salinity. Different brine salinity affects the water-rock reaction differently. In order to study the effect of the fluid salinity on the stress sensitivity of shale, we experimented with saline water of different salinity. $\mathrm{NaCl}$, as the main component of formation fluids, was selected for the experiments. The plunger cores were soaked in $\mathrm{NaCl}$ brine of salinity $0 \mathrm{mg} / \mathrm{L}, 5000 \mathrm{mg} / \mathrm{L}$, and $15000 \mathrm{mg} / \mathrm{L}$, respectively (the distilled water and $5000 \mathrm{mg} / \mathrm{L} \mathrm{NaCl}$ brine were tested in cores 1 and 3, respectively). After the reaction was complete, core 4 was removed and placed in the thermostat. The temperature was set to $60^{\circ} \mathrm{C}$, and the core was dried for $48 \mathrm{~h}$. The stress sensitivity experiments and acoustic tests were carried out on core 4 after the cores had cooled down. We could determine the effect of salinity on the water-shale interaction.

2.2.3. Stress Sensitivity Experiments of Shale with Different Soaking Time. In addition to the effects of the brine type and salinity on stress sensitivity, the effects of the soaking time on stress sensitivity should also be considered. The degree of interaction between water and shale is controlled mainly by these three external factors. In order to quantify the effects of hydration on the stress sensitivity of shale, the 


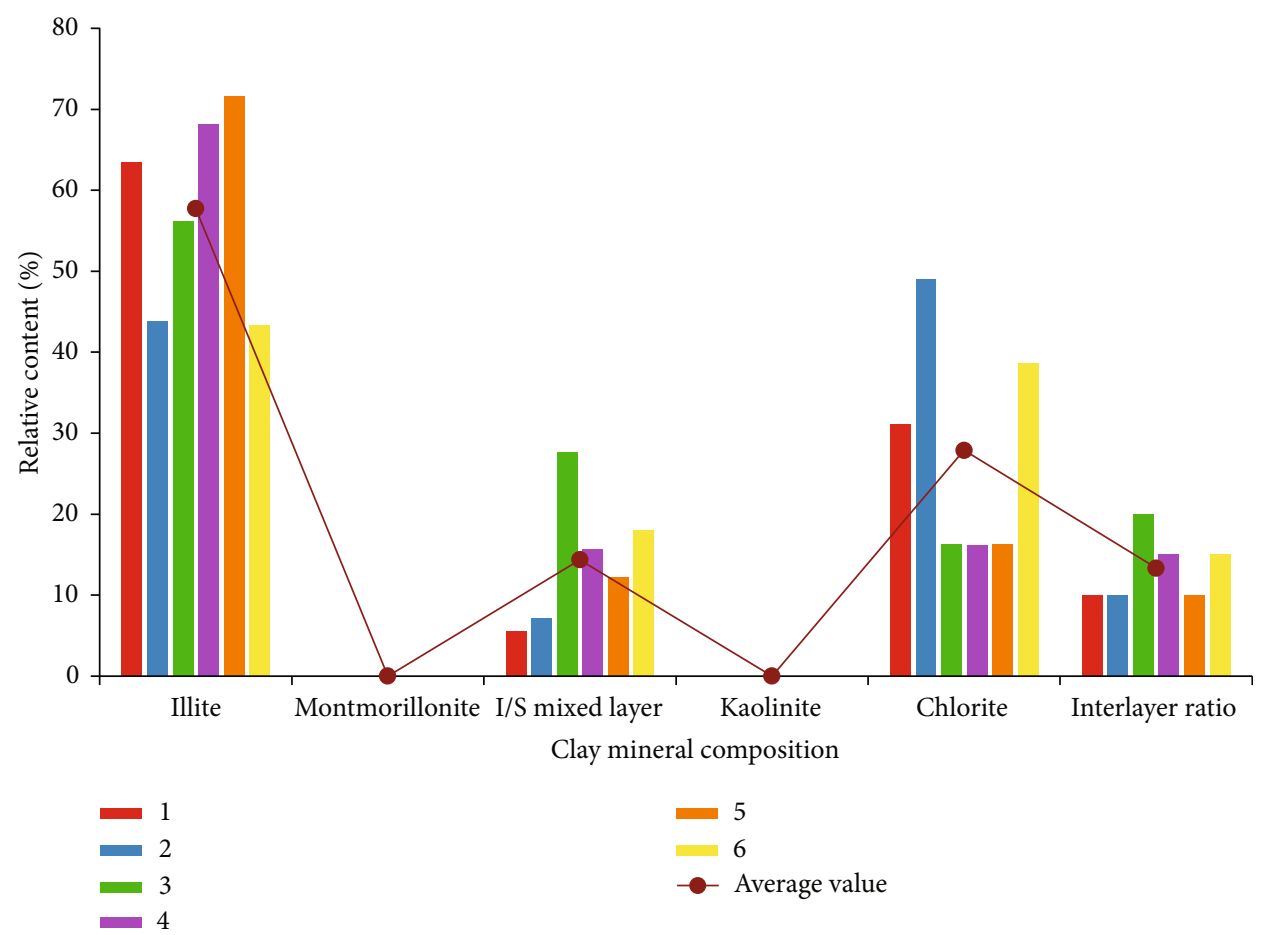

FIGURE 1: Experimental results of total rock analysis.

interaction time between the shale and brine must be considered. In this experiment, $5000 \mathrm{mg} / \mathrm{L}$ of $\mathrm{NaCl}$ was used as the experimental fluid. Three cores were separately immersed in $5000 \mathrm{mg} / \mathrm{L} \mathrm{NaCl}$ brine for $6 \mathrm{~h}, 24 \mathrm{~h}$, and $48 \mathrm{~h}$ (samples for $48 \mathrm{~h}$ have been done). After the reaction, the plunger cores were removed and dried in a thermostat for $48 \mathrm{~h}$ at $60^{\circ} \mathrm{C}$. Sound wave tests and stress sensitivity tests were carried out on cores 5 and 6 after drying. The results of the experimental were compared with those of the original rock.

\section{Results and Discussion}

Research into the effects of the interactions of water and shale on the stress sensitivity of organic-rich shale can aid us in understanding the impact of the entry of water into a reservoir on the reservoir development. By studying the stress sensitivity of shale under different degrees of interactions between the shale and water, we can identify the mechanism of well instability. Moreover, we can put forward measures for developing the shale reservoir.

3.1. Sample Characteristics. For a better understanding of the samples, in this study, we studied the mineral composition and microstructure of the samples by X-ray diffraction and SEM experiments, in addition to the pore permeability characteristics. The experimental results are presented in Figures 1-3.

Figures 1 and 2 show that the mineral composition of organic shale in the Ordos Basin is composed mainly of clay minerals. The clay minerals are mainly illite and also contain a partial illite-montmorillonite mixed layer. According to previous studies [41, 42], the presence of clay minerals is the main reason for the interactions between water and shale. Owing to either the adsorption of water molecules by illite or the expansion of the mixed layer after water absorption, a force between water and shale is produced. This either causes the cracks in the shale to expand or generates new cracks.

Figure 3(a) shows the presence of well-developed microfractures in the shale. They provide a channel for the working fluid to enter the reservoir and cause the reservoir to be more vulnerable to the water-rock interactions. Figure 3(b) shows the occurrence of clay minerals in the shale sample. Whereas the presence of clay minerals can be determined, it is challenging to distinguish the types of clay minerals based on the scanning electron microscopy results. Figure 3(b) shows that the clay minerals in the shale are distributed mainly around the pores. This may result in higher reaction rates with water. The interaction between shale and water alters the structure of shale, thus affecting its stress sensitivity.

3.2. Effect of Types of Brine. We may obtain different results when the shale reacts with different brine, under similar conditions. According to a previous investigation [42], whereas $\mathrm{KCl}$ can inhibit the expansion of clay minerals effectively, $\mathrm{NaCl}$ can do so only to a certain degree. Therefore, the changes in the pore structure produced by different brine may differ. The stress sensitivity and acoustic characteristics of four adjacent cores were measured before and after the brine immersion. The experimental results are shown in Figures 4-7.

Figures 4-6 show that the initial permeability of the cores increases several times, even tens of times, after soaking in distilled water or the various brine. The experimental results reveal that the largest change in permeability is in distilled 


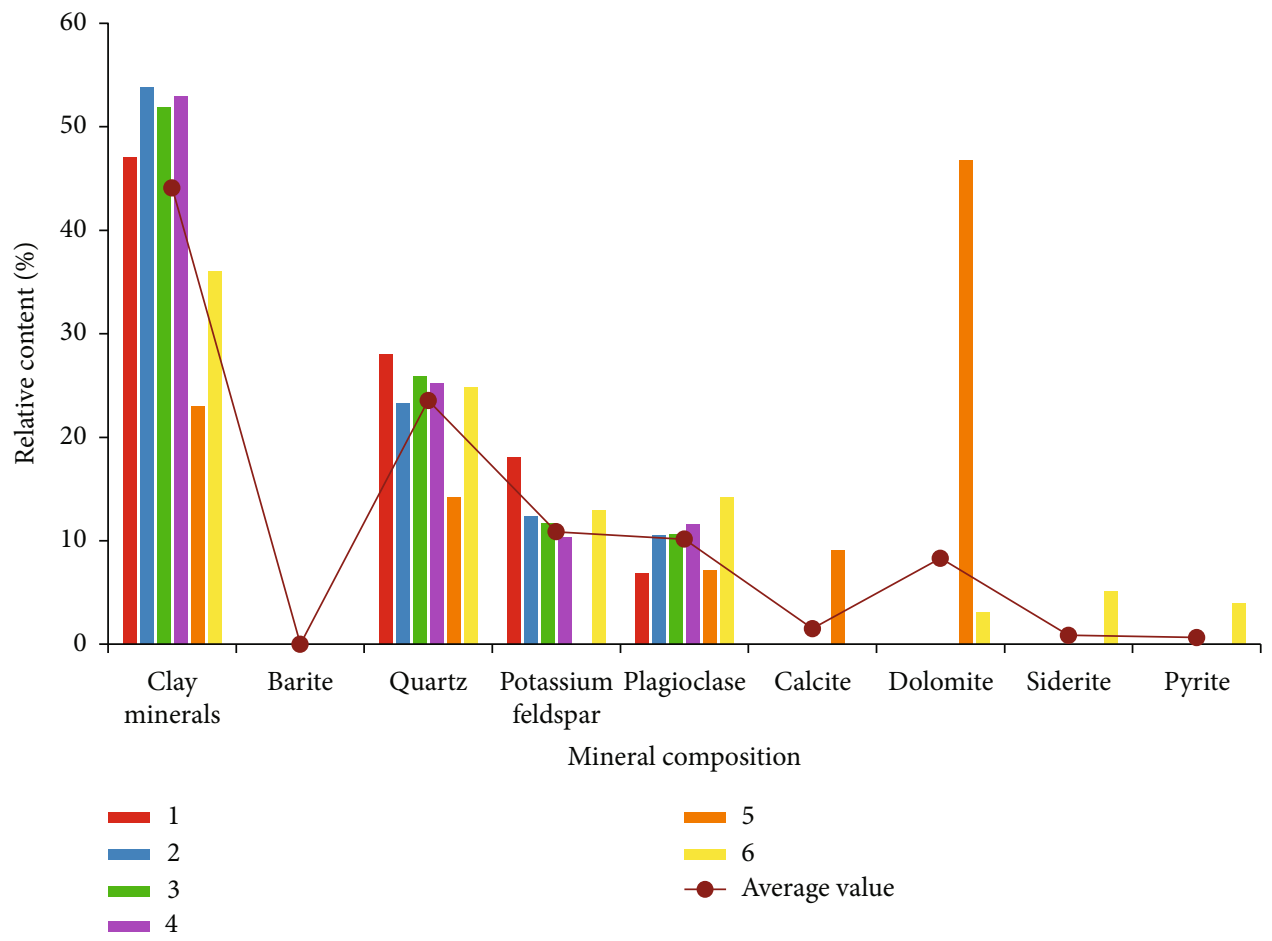

FIGURE 2: Experimental results of composition of clay minerals.

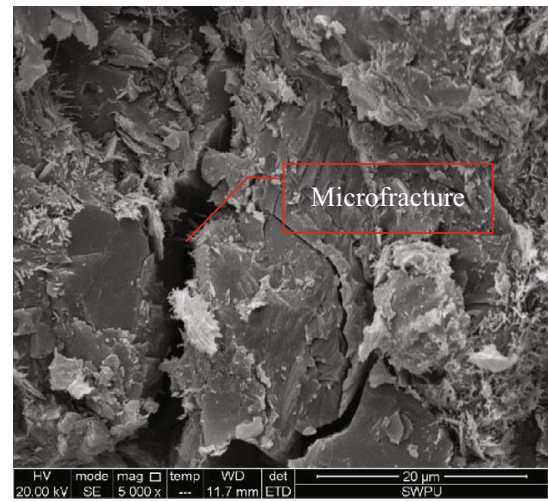

(a)

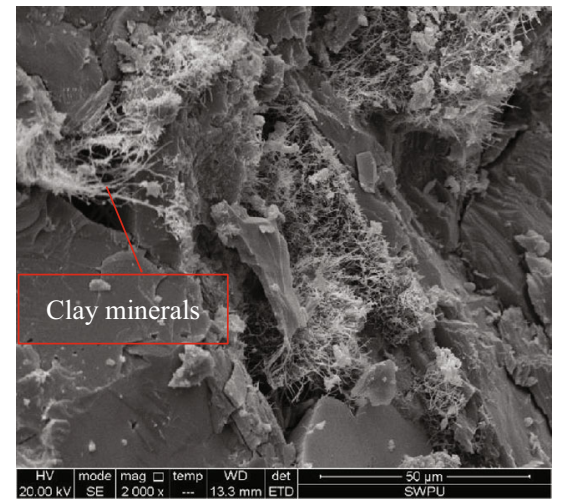

(b)

Figure 3: Examples of (a) microfractures and (b) clay minerals in shale samples.

water, followed by $\mathrm{KCl}$. The smallest change is in the $\mathrm{NaCl}$ solution. Permeability is a comprehensive result of various factors and is closely related to the pore structure of the core. As is evident from Figure 4, the initial permeability of shale after reacting with distilled water is ten times higher that of the original core. The enlargement of seepage channels can be considered the result of the joint action of crack growth and new crack formation. The stress sensitivity results before the interaction with distilled water reveal that when the pressure of shale increases to $10 \mathrm{MPa}$, the permeability of the reservoir becomes very low. Moreover, the seepage channel in the shale is compacted. Finally, the stress sensitivity coefficient is above 0.9. This indicates that the reservoir has been subjected to extensive stress sensitivity damage. The initial permeability of the shale increases after the reaction with the distilled water. In the process of pressure increase, the rate of permeability decreases gradually. The permeability recovered finally is equivalent to the initial permeability (the value before the interaction between water and shale). This demonstrates that after the shale and water interact, the fracture in the reservoir expands, the seepage channel of the reservoir enlarges, and the final stress sensitivity coefficient decreases. Figure 5 shows similar characteristics. It indicates that the inhibition of the water-rock interactions by $\mathrm{K}^{+}$ is not apparent. According to previous research results [42], $\mathrm{K}^{+}$mainly inhibits water-sensitive clay minerals such as montmorillonite. The shale used in this study is organicrich shale, and its clay mineral composition is mainly illite 


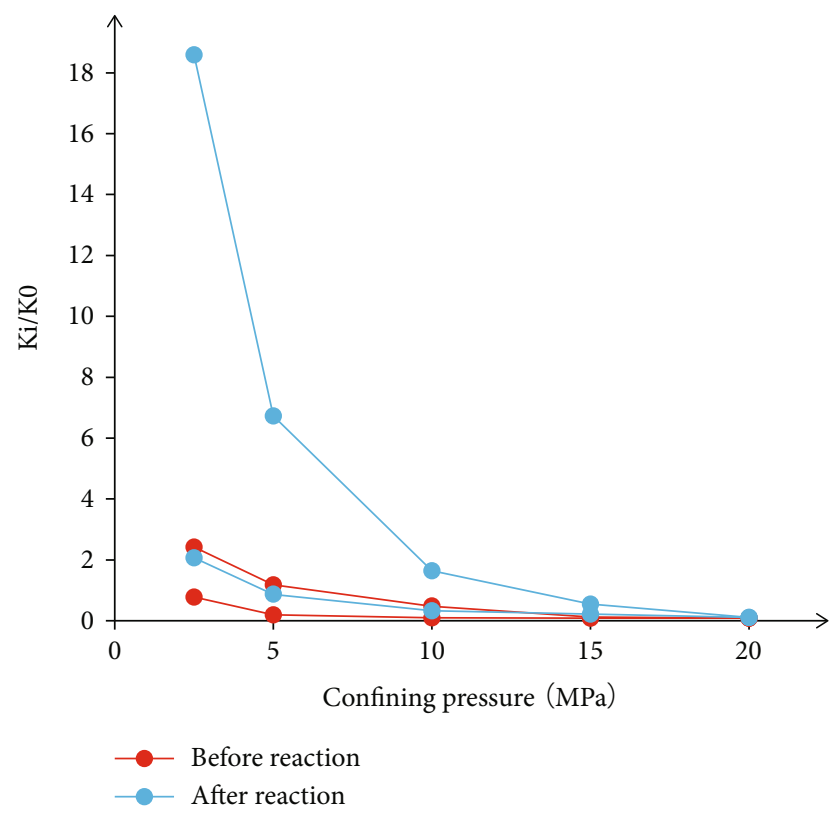

FIGURE 4: Stress sensitivity of shale before and after interactions with distilled water for $48 \mathrm{~h}$.

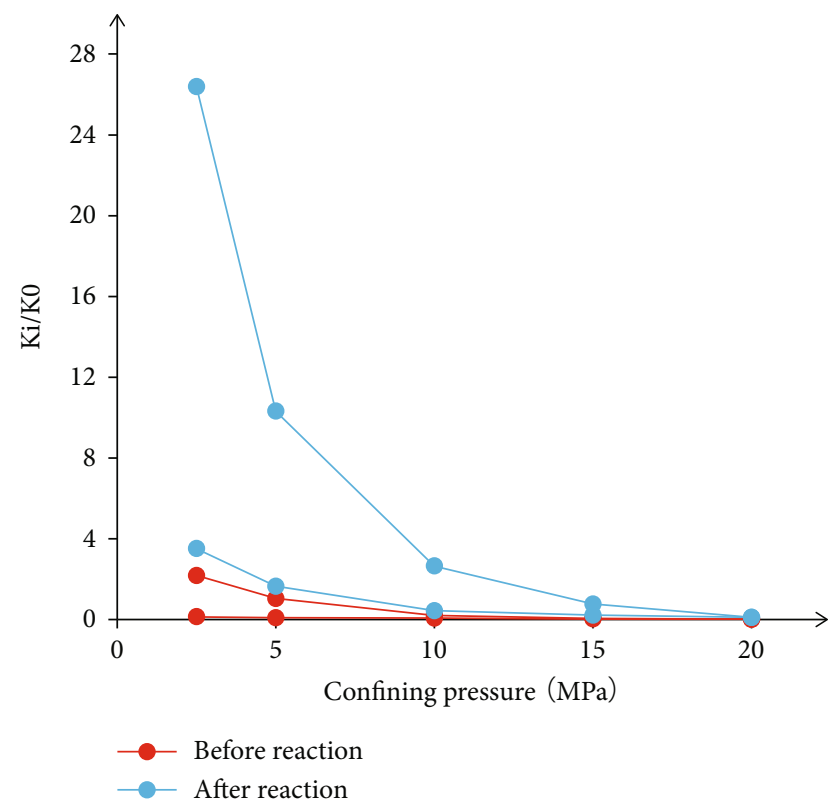

FIGURE 5: Stress sensitivity of shale before and after interaction with $5000 \mathrm{mg} / \mathrm{L} \mathrm{KCl}$ solution for $48 \mathrm{~h}$.

and partly a illite-montmorillonite mixed layer. Therefore, it does not exhibit a strong inhibition effect. From Figure 6, the initial permeability of shale after reacting with $\mathrm{NaCl}$ solution increases although insignificantly. Moreover, the stress sensitivity coefficient is similar to that from before the interaction with water. As is evident from Figures 4-6, the effect of the saltwater type on the interaction of water and shale is not apparent. Figure 7 shows that irrespective of the type of brine that reacts with the core, the stress sensitivity and

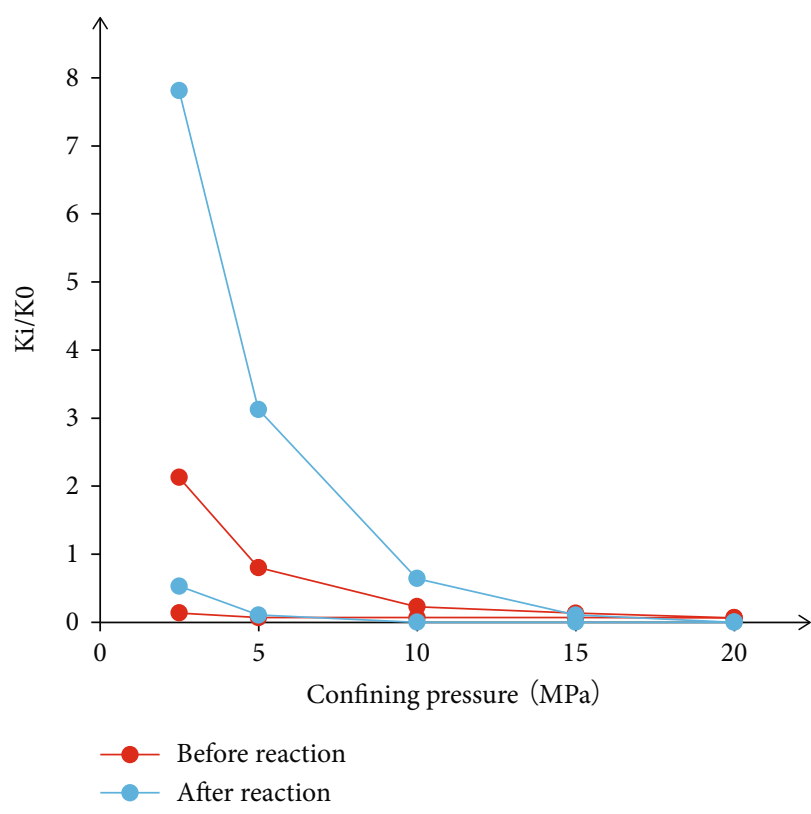

FIGURE 6: Stress sensitivity of shale before and after interaction with $5000 \mathrm{mg} / \mathrm{L} \mathrm{NaCl}$ solution for $48 \mathrm{~h}$.

stress-sensitive damage of the reservoir are reduced after $48 \mathrm{~h}$. However, the reservoir as a whole still exhibits very strong stress-sensitive damage. Whereas the original stress sensitivity coefficient was above 0.9 , it is below 0.9 after the reaction for all the samples. Figures 4-7 also show that the stress sensitivity increases with a decrease in the initial permeability for organic shale with microfracture development. This is in agreement with You et al. [28].

The experimental results also show that the change in the initial permeability after the reaction with the different brine is different. The initial permeability of the shale reacting with distilled water is higher than that of the others. This indicates that the primary fracture of shale is more developed. We also observe that the stress sensitivity of shale is weakened marginally and the permeability of the reservoir is increased significantly after the reaction with the different types of brine. This is a result of the water-shale interactions. Water molecules are adsorbed at the crack tip of the shale. This decreases the strength of the shale and causes further cracking. This also increases the contact area between the shale and water, thereby increasing the initial permeability of the shale. In order to better explain the causes of the experimental results, it is necessary to analyze the results of the acoustic characteristic tests, which are shown in Figure 8.

Figure 8 shows that the attenuation coefficient of an acoustic wave increases apparently after the interaction with saline water. The pore structure of the shale has undergone dramatic changes because of the interactions between the shale and brine, resulting in a large number of microcracks. The development of microcracks increases the void volume of the shale. This reduces the velocity of sound waves and thus increases the time difference between sound waves and the attenuation coefficient. Simultaneously, we observe that the attenuation coefficient of shale increases marginally after the interaction with $\mathrm{KCl}$. This may be owing to the inhibition 


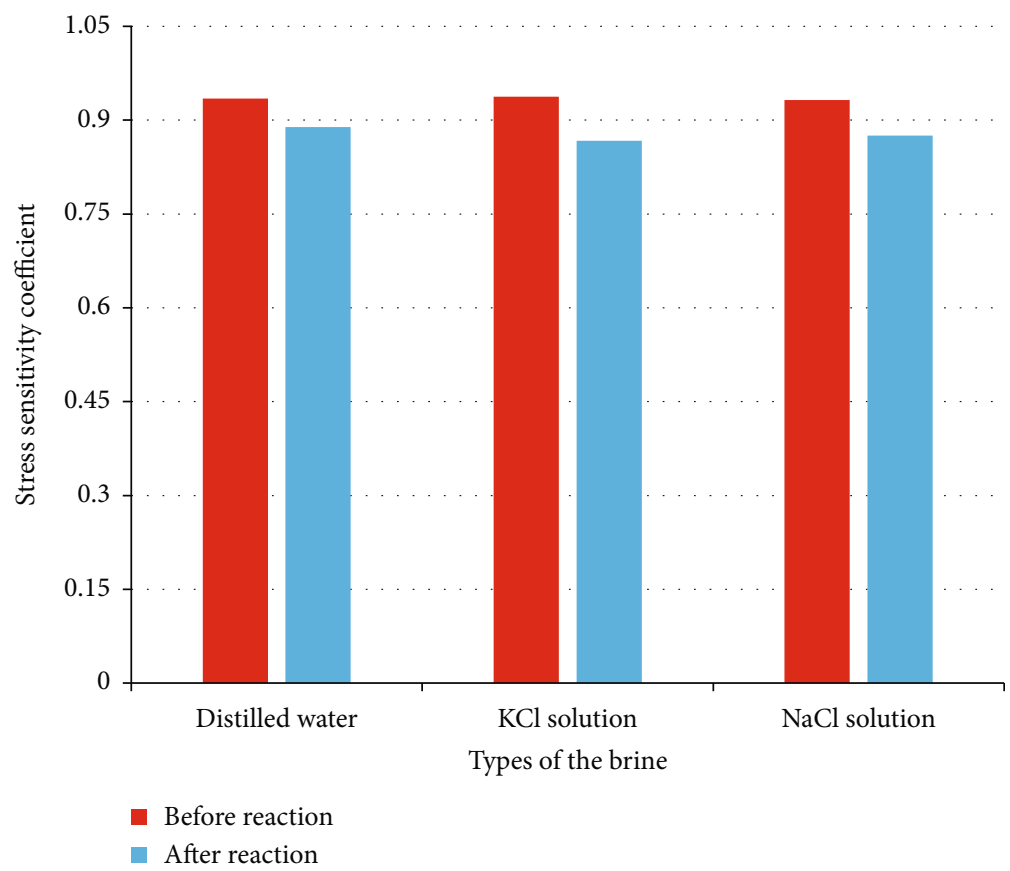

FIGURE 7: Stress sensitivity coefficient of shale before and after interaction with different brine for $48 \mathrm{~h}$.

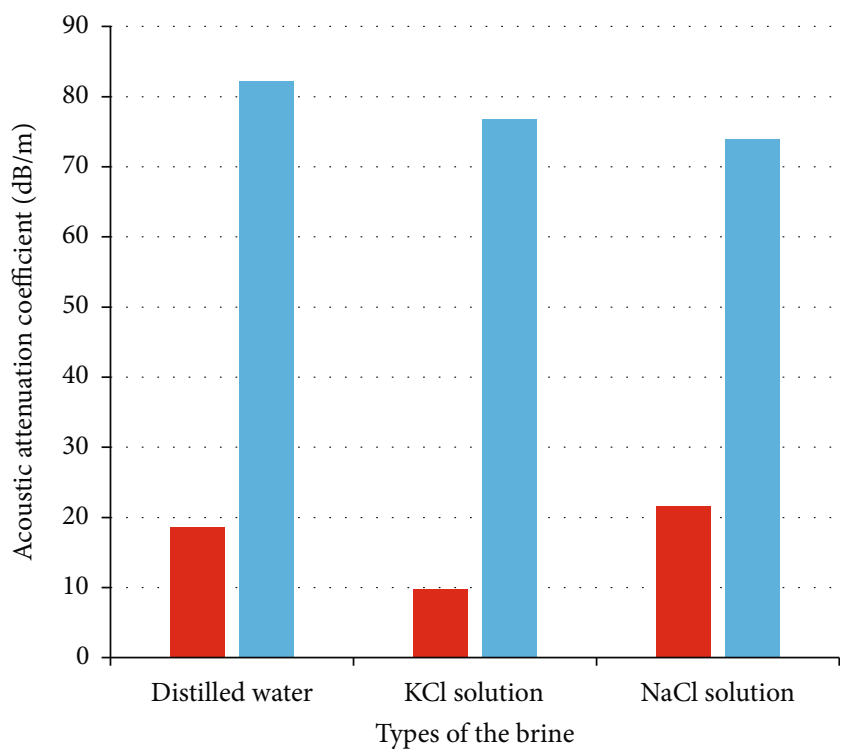

- Before reaction

- After reaction

Figure 8: Acoustic attenuation coefficient of shale before and after interaction with different brine for $48 \mathrm{~h}$.

of the interactions between the water and clay minerals to a certain extent by $\mathrm{K}^{+}$, so that less shale has been destroyed.

The results of the acoustic attenuation coefficient also reveal that the variation in the initial permeability is larger for a larger variation in the acoustic attenuation coefficient. After reacting with distilled water, the initial permeability of the shale becomes nearly ten times higher than that of the original. The attenuation coefficient of the acoustic wave changes the most. It is evident that the attenuation coefficient of the acoustic wave reflects the degree of interaction between water and shale to a certain extent. However, there is no direct correlation between the attenuation coefficient and the stress sensitivity. The internal structure and initial permeability of the shale as well as its mineral composition should be considered while analyzing the stress sensitivity of shale. Therefore, the results of the acoustic attenuation coefficient also establish that shale reacts violently with brine. This changes the internal structure of the shale and affects its stress sensitivity.

It is evident that the brine type does not influence the interactions of water and shale significantly. All the studied brine types cause a severe water-rock reaction. The result of the interaction of water and shale is to increase the permeability of shale, promote the development of fractures, and reduce the stress sensitivity of the shale reservoir marginally. From the perspective of drilling, the interactions between water and shale reduce the strength of the shale, change its stress distribution, and cause wellbore collapse. However, the influence of the type of brine is relatively marginal. Therefore, appropriate additives should be added to the drilling fluid to inhibit the interactions of water and shale. In the subsequent stimulation process, the interaction of water and shale promotes the generation of new fractures. This, in turn, promotes a fracturing effect, increases the permeability of reservoirs, and reduces the stress sensitivity of reservoirs. The attenuation coefficient of the acoustic wave reflects the changes in the internal structure of shale after interactions with water to a certain extent. Furthermore, it corresponds to the change in permeability after the interactions of water and shale. 


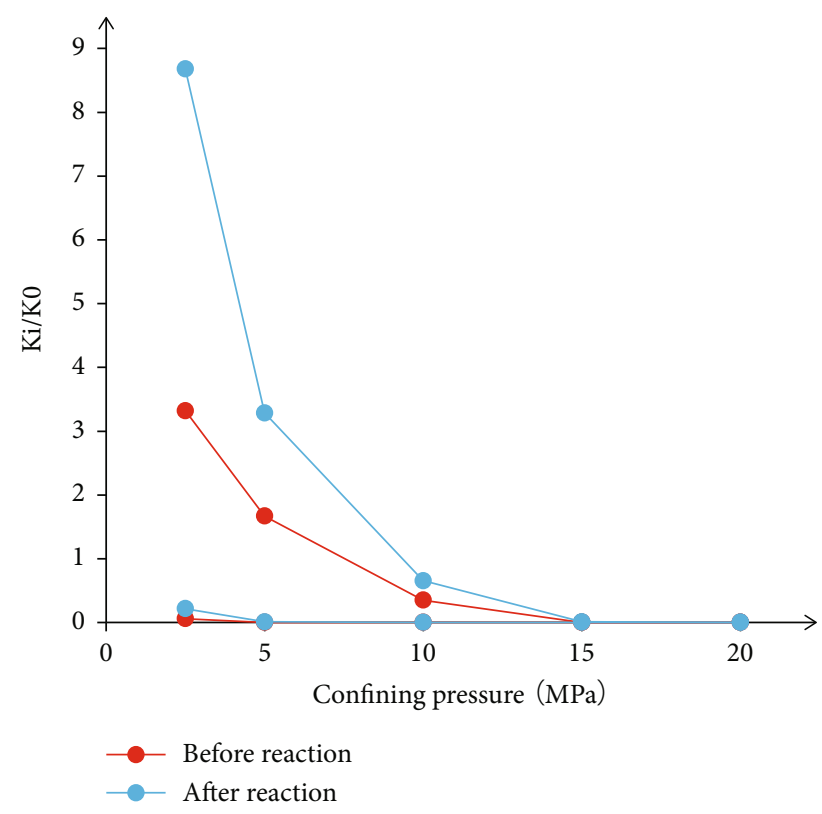

FIGURE 9: Stress sensitivity of shale before and after interaction with $15000 \mathrm{mg} / \mathrm{L} \mathrm{NaCl}$ solution for $48 \mathrm{~h}$.

3.3. Effect of Salinity of Brine. According to previous studies, a higher salinity results in a lower osmotic pressure difference between the interior and exterior of the crystalline layer of the clay minerals. A larger osmotic pressure difference results in increased swelling of the clay minerals. The clay minerals of the organic-rich shale used in these experiments are composed mainly of illite, with a marginal amount of an illitemontmorillonite mixed layer. Therefore, a change in salinity may affect the stress sensitivity of reservoirs as well. In order to study the effect of the salinity of different brine on the stress sensitivity, distilled water (Figure 4), $5000 \mathrm{mg} / \mathrm{L} \mathrm{NaCl}$ solution (Figure 6), and $15000 \mathrm{mg} / \mathrm{L} \mathrm{NaCl}$ solution were reacted with shale for $48 \mathrm{~h}$ before the stress sensitivity tests. The experimental results are shown in Figures 9 and 10.

The effects of distilled water and $5000 \mathrm{mg} / \mathrm{L} \mathrm{NaCl}$ solution on the stress sensitivity of shale are explained in Section 3.1. Figure 7 shows that the initial permeability of shale increases two times as much after the interaction with $15000 \mathrm{mg} / \mathrm{L} \mathrm{NaCl}$. Figures 4, 6, and 9 show that the initial permeability of shale increased after the interactions with brine. The increase in initial permeability decreases with an increase in brine salinity. This indicates that brine salinity affects the interactions between shale and water. As is evident from Figure 10, the change in the stress sensitivity of shale decreases with an increase in the salinity of brine. The stress sensitivity coefficient of shale reacted with the distilled water and that of shale reacted with the $5000 \mathrm{mg} / \mathrm{L}$ $\mathrm{NaCl}$ solution decreased by 0.05 . However, the stress sensitivity of shale decreased by 0.007 after it reacted with the $15000 \mathrm{mg} / \mathrm{L} \mathrm{NaCl}$ solution. The stress sensitivity coefficient of the shale after the interaction attained 0.975 , which represents an insignificant change.

The experimental results demonstrate that salinity affects the interactions of water and shale. The initial permeability increases substantially after shale reacts with brine of different salinity. However, the change rate of permeability decreases with an increase in salinity. According to a previous investigation [42], the salt concentration affects the expansion of clay minerals. An increase in salinity reduces the difference in concentration between the solution and the crystal layer of clay minerals, thereby reducing the interactions between shale and water. However, the experimental results demonstrate that the brine types of the various salinity levels undergo intense water-rock reactions with shale and that the initial permeability of shale is substantially improved after its reaction with brine. This could be a result of primary fracture propagation and microfracture development. The stress sensitivity coefficient of shale decreases for all the concentrations of saline water. However, the amount of decrease is not identical. This may be a result of the change in the internal structure of the shale. In order to understand this phenomenon more deeply, experiments on acoustic characteristics should be combined with these. The experimental results of the acoustic attenuation coefficient are shown in Figure 11.

Figure 11 shows that the acoustic attenuation coefficients of shale that reacted with the brine of different concentrations increased to varying degrees. The experimental results also reveal that the attenuation coefficient of an acoustic wave decreases with an increase in the salt concentration. This indicates that the degree of change in the internal structure of shale decreases. The interactions of shale and water tend to weaken with an increase in the salt concentration.

This could be because of some role played by the illitemontmorillonite mixed layer in the shale. According to the results of Section 3.1, the type of brine does not play a key role in the interactions between shale and water. This indicates that the interaction mechanism is different from that of mudstone. The main cause of interaction between shale and water is illite. It adsorbs water molecules so that the strength of the crack tip is reduced and expanded. The characteristics of shale after interactions with brine of different concentrations can be considered to be dominated by the role of the illite-montmorillonite mixed layer in the shale. This results in the clay minerals expanding differently in different brine concentrations.

With regard to the effects of brine salinity on the stress sensitivity of shale, higher salinity results in a lower stress sensitivity coefficient of shale. Lower brine salinity results in lesser inhibition of the interactions of water and shale. This is more conducive to the expansion of microfractures and the generation of new fractures. Therefore, when a waterbased drilling fluid is used in the drilling process, in addition to adjusting the density and rheological parameters, the salinity of brine can be appropriately increased. During the fracturing process of subsequent modifications, we can consider increasing the brine salinity to alleviate the reservoir damage caused by stress sensitivity.

3.4. Effect of Soaking Time. It is inconvenient for water to enter shale because shale is characterized by low porosity and permeability. Therefore, the duration of immersion exerts an influence on the interaction between shale and water and may exert different influences on the stress sensitivity. The 


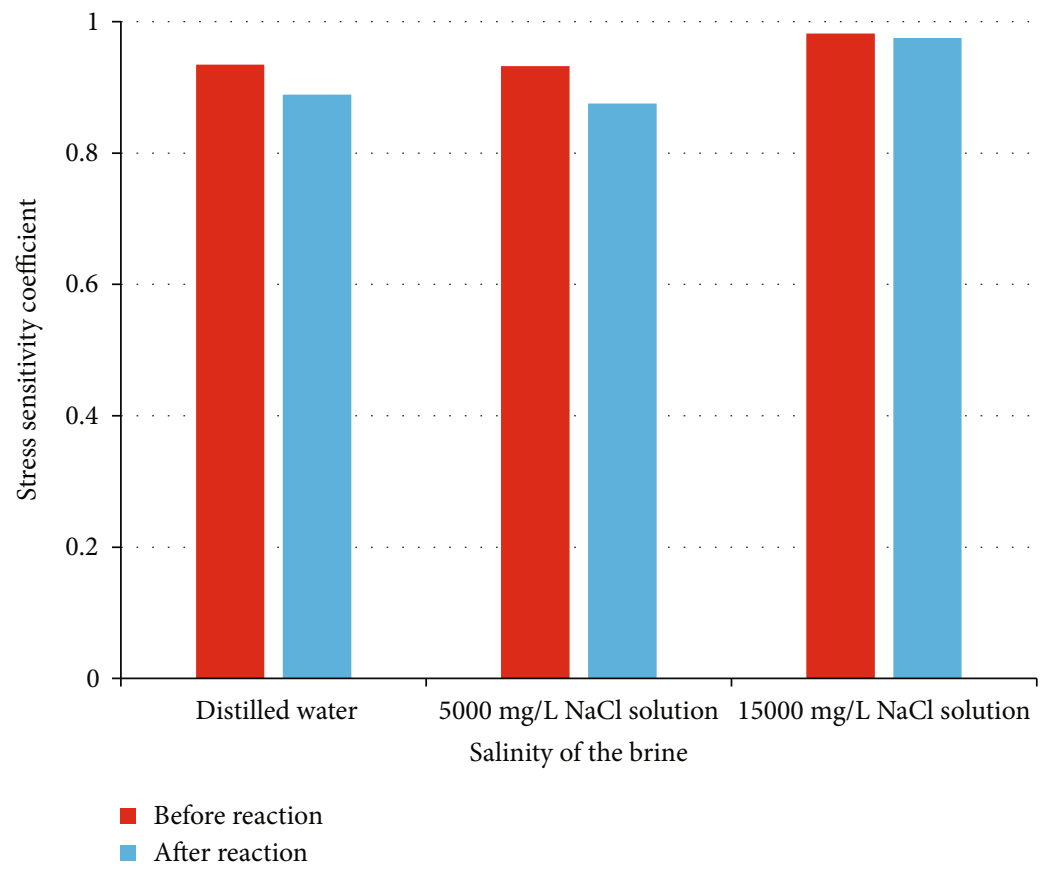

Figure 10: Stress sensitivity coefficient of shale before and after interaction with different salinity of brine for $48 \mathrm{~h}$.

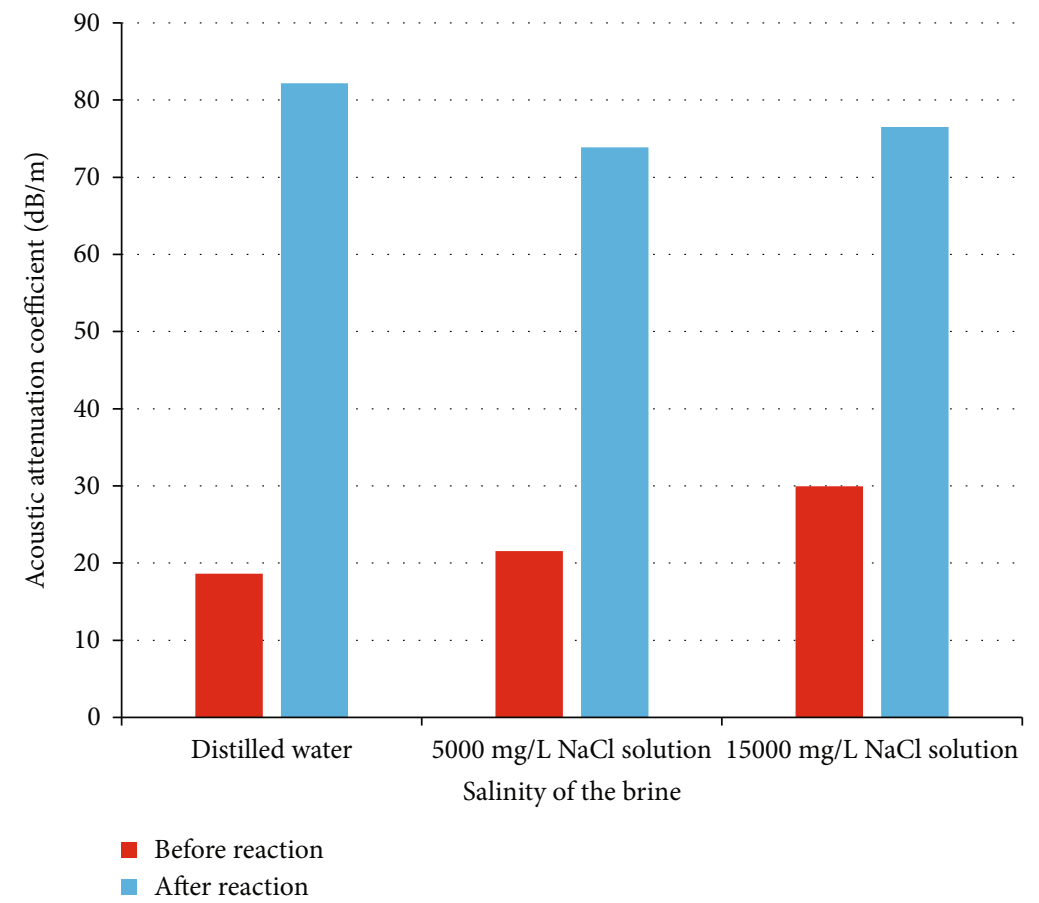

Figure 11: Acoustic attenuation coefficient of shale before and after interaction with different salinity of brine for $48 \mathrm{~h}$.

$5000 \mathrm{mg} / \mathrm{L} \mathrm{NaCl}$ solution was reacted with the shale for $6 \mathrm{~h}$, $24 \mathrm{~h}$, and $48 \mathrm{~h}$ (the latter is shown in Figure 6). The stress sensitivity before and after the reaction was measured. The experimental results are shown in Figures 12-14.

From Figure 12, it can be shown that the initial permeability of the shale increases from $2.24 \times 10^{-3} \mathrm{mD}$ to $3.59 \times$ $10^{-3} \mathrm{mD}$ after $6 \mathrm{~h}$ of reaction with brine. It can also be evident that the variation in the stress sensitivity curve is similar to that in the other curves in that it first decreases rapidly and then decreases slowly gradually after $10 \mathrm{MPa}$. The stress sensitivity coefficients of shale before and after the action of brine are all 0.94 . Figure 13 shows that the initial permeability of shale increases from $2.50 \times 10^{-3} \mathrm{mD}$ to $5.72 \times 10^{-3} \mathrm{mD}$ after $24 \mathrm{~h}$ of saltwater interaction. Meanwhile, the stress 


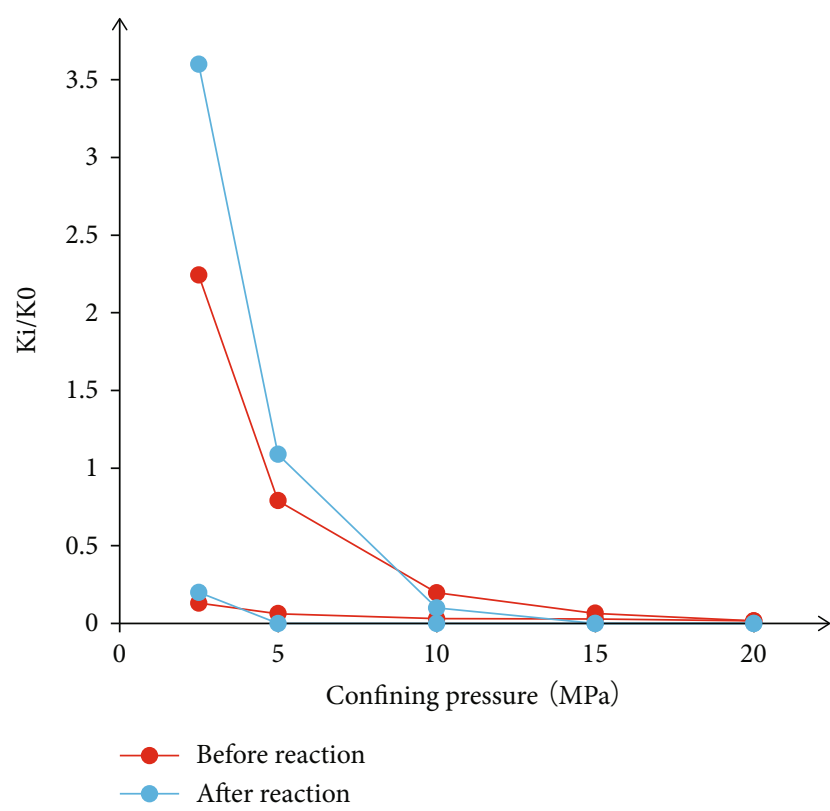

FIGURE 12: Stress sensitivity of shale before and after interaction with $5000 \mathrm{mg} / \mathrm{L} \mathrm{NaCl}$ solution for $6 \mathrm{~h}$.

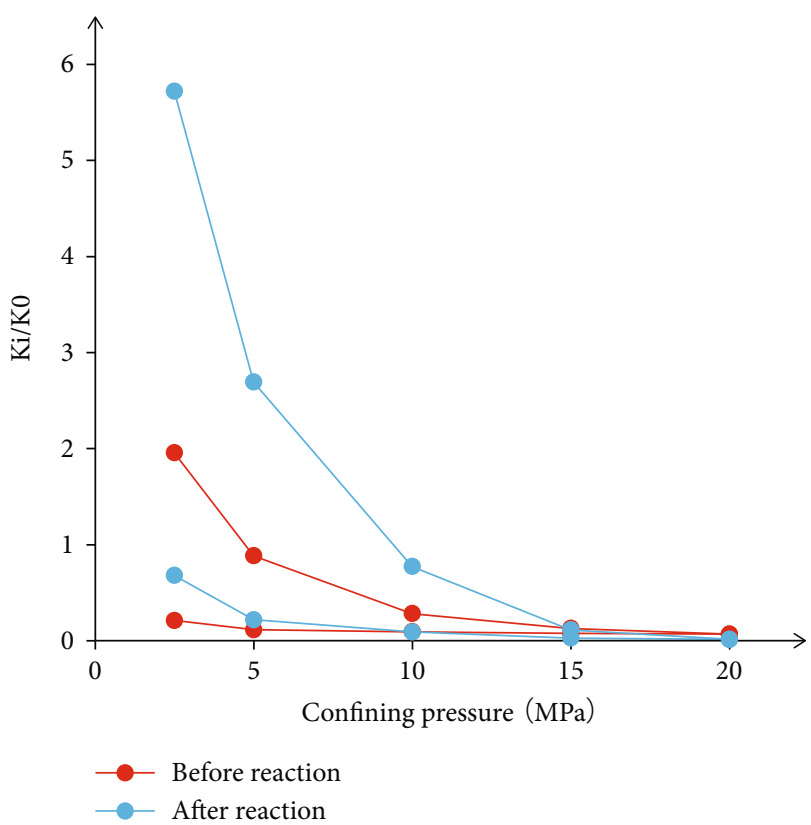

FIGURE 13: Stress sensitivity of shale before and after interaction with $5000 \mathrm{mg} / \mathrm{L} \mathrm{NaCl}$ solution for $24 \mathrm{~h}$.

sensitivity decreases marginally. The results shown in Figure 5 are explained in Section 3.1. From Figures 6 and $12-14$, we show that the initial permeability of shale increases with an increase in the reaction time with brine. Meanwhile, the stress sensitivity coefficient shows a downward trend.

The experimental results show that the time of interaction with brine affects the permeability and stress sensitivity of the shale. The permeability increases and stress sensitivity coefficient decreases with an increase in the reaction time.
This is because more water enters the shale with increased contact time between the shale and brine, which enlarges the contact area between water and shale and promotes the water-shale interactions. Macroscopically, the higher the permeability, the lower the stress sensitivity of the shale. From the experimental results, the main factor affecting stress sensitivity is the change in internal structure, which is reflected in the change in the attenuation coefficient of an acoustic wave. The experimental results for the acoustic attenuation coefficient are shown in Figure 15.

As is evident from Figure 15, the increase in the acoustic attenuation coefficient of shale varies with the reaction time in brine and on the whole exhibits characteristics similar to those of the change in stress sensitivity. Moreover, the variation in the acoustic attenuation coefficient is also related to the variation in the stress sensitivity coefficient. The experimental results also demonstrate that a change in the internal structure of shale influences the stress sensitivity substantially and that a change in initial permeability corresponds to a change in stress sensitivity at the macro level.

The attenuation coefficient of the acoustic wave after saltwater immersion increases with an increase in the immersion time. This indicates the presence of structural defects in the shale. This type of defect is mainly caused by fracture propagation and microfracture development, which enlarges the seepage channel and increases the permeability of shale. According to previous research [29], the development of microcracks increases the stress sensitivity of shale. Thus, it is evident from the experimental results that the influence of fracture propagation is higher than that of microcracks. This causes a decrease in stress sensitivity with an increase in the water-rock interaction time.

With regard to the effect of the water-rock interaction duration on the stress sensitivity of shale, the longer the interaction time, the higher the permeability of the shale and the smaller the stress sensitivity coefficient. In order to prevent wellbore instability during drilling, the contact time between shale and a water-based working fluid should be minimized. In the subsequent stage of fracturing, the contact area between the water-based working fluid and the shale can be increased within a certain range, such that the permeability of the reservoir can be increased and the stress sensitivity damage of the reservoir reduced. Because long contact time causes difficulties in terms of fracturing fluid backflow, the time should be limited to a reasonable range.

\section{Conclusions}

In this work, the effects of the interaction between water and shale on the stress sensitivity of organic-rich shale in brine were studied. The study was conducted with a focus on the type of brine, salinity of the brine, and duration of the exposure. Furthermore, the attenuation coefficient of sound waves was also used to substantiate the results. The mechanism by which the interaction of water and shale affects the stress sensitivity of shale was analyzed. Moreover, the following recommendations and measures were also put forward for field operations: 


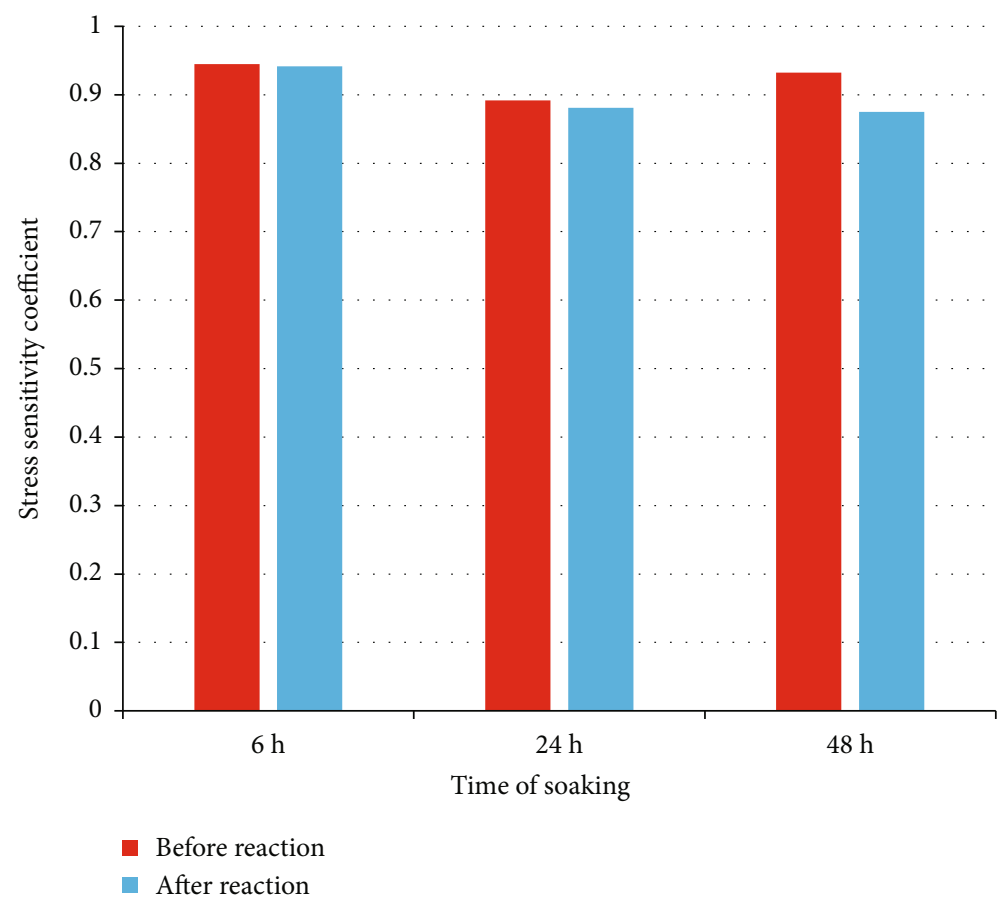

FIGURE 14: Stress sensitivity coefficient of shale before and after interaction with $5000 \mathrm{mg} / \mathrm{L} \mathrm{NaCl}$ solution for different time.

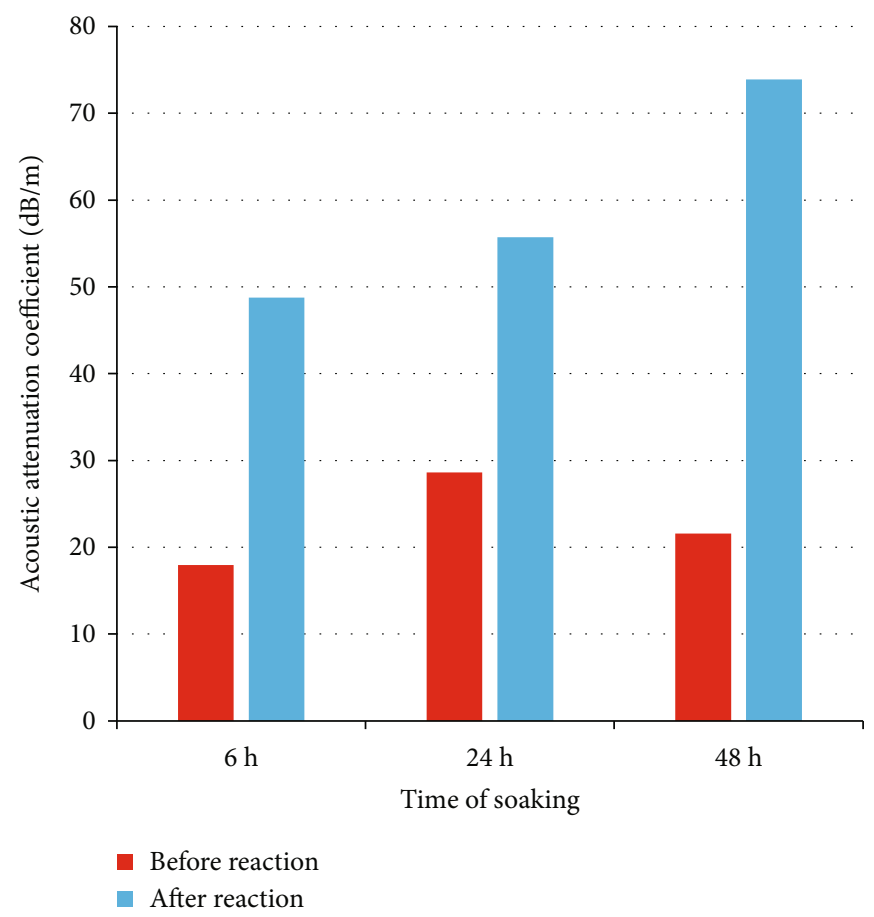

Figure 15: Acoustic attenuation coefficient of shale before and after interaction with $5000 \mathrm{mg} / \mathrm{L} \mathrm{NaCl}$ solution for different time.

(1) The interaction of water and shale increases the permeability of shale and reduces its stress sensitivity. Shale exhibits strong stress sensitivity when the permeability is excessively low. Moreover, the effect of crack propagation on stress sensitivity is higher than that of new microcracks
(2) The changes in the attenuation coefficients of acoustic waves are related to the change in the stress sensitivity of shale. The higher the attenuation coefficient of the acoustic wave, the larger the change in the shale structure, the higher its permeability, and the smaller the stress sensitivity coefficient 
(3) The effect of saltwater type on stress sensitivity is not apparent. The inhibition of $\mathrm{KCl}$ is aimed mainly at montmorillonite, which was not prevalent in our shale samples. The salinity of brine affects the interaction between shale and water, thus affecting the stress sensitivity of the shale. After reacting with $15000 \mathrm{mg} / \mathrm{L}$ brine, the stress sensitivity coefficient of shale did not decrease significantly compared with that before action, all of which were above 0.97 . However, after reacting with distilled water or $5000 \mathrm{mg} / \mathrm{L}$ brine, the stress sensitivity coefficient of shale decreased significantly, and all of them decreased to less than 0.9. This is mainly because a change in salt concentration affects the expansion degree of the illite-montmorillonite mixed layer. Relatively, the duration of the water-shale interaction exerts a higher impact on the stress sensitivity of the shale. Longer water exposures, corresponding to an increased duration of water-shale interactions, result in higher impacts on the stress sensitivity of shale. After 6 hours of shale-brine interaction, the stress sensitivity coefficient of shale is as high as 0.93 , while after 48 hours of shale-brine interaction, the stress sensitivity coefficient of shale is reduced to 0.88

(4) In the process of drilling, the salinity of the drilling fluid should be maximized and the contact time between the water-based drilling fluid and shale should be reduced to ensure wellbore stability. In the process of fracturing, the permeability of shale can be increased by properly reducing the salinity of the brine and increasing the soaking time, which can also reduce the stress sensitivity damage to the shale

\section{Data Availability}

The experimental data used to support the findings of this study are included within the article.

\section{Conflicts of Interest}

The authors declare that they have no conflicts of interest.

\section{Acknowledgments}

This research was supported by the National Natural Science Foundation of China (NSFC) (Grant Nos. 41772151 and 41872167). We also thank the Young Scientific and Technological Innovation Team of Petroleum Physics in Unconventional Strata of Southwest Petroleum University (No. 2018CXTD13).

\section{References}

[1] J. Xiong, X. Liu, and L. Liang, "On the differences of reservoir characteristics of the upper and the lower Longmaxi Formation shale," Journal of Northwest University: Natural Science Edition, vol. 45, no. 4, pp. 623-630, 2015.

[2] R. Gholami, H. Elochukwu, N. Fakhari, and M. Sarmadivaleh, "A review on borehole instability in active shale formations: interactions, mechanisms and inhibitors," Earth-Science Reviews, vol. 177, pp. 2-13, 2018.

[3] B. Jia, J. S. Tsau, and R. Barati, "A workflow to estimate shale gas permeability variations during the production process," Fuel, vol. 220, pp. 879-889, 2018.

[4] M. A. Sayed, G. A. al-Muntasheri, and F. Liang, "Development of shale reservoirs: knowledge gained from developments in North America," Journal of Petroleum Science and Engineering, vol. 157, pp. 164-186, 2017.

[5] Y. Ma, X. Cai, and P. Zhao, "China's shale gas exploration and development: understanding and practice," Petroleum Exploration and Development Online, vol. 45, no. 4, pp. 589-603, 2018.

[6] S. Wang, "Shale gas exploitation: status, problems and prospect," Natural Gas Industry B, vol. 5, no. 1, pp. 60-74, 2018.

[7] L. Zhao, W. Gao, L. Zhao, and S. Ma, "Experimental study on stress sensitivity of shale reservoirs and analysis of influencing factors," Journal of Chongqing University of Science and Technology: Natural Science Edition, vol. 15, no. 3, pp. 43-46, 2013.

[8] W. Xiao, T. Li, M. Li, J. Zhao, L. Zheng, and L. Li, "Evaluation of the stress sensitivity in tight reservoirs," Petroleum Exploration and Development, vol. 43, no. 1, pp. 115-123, 2016.

[9] A. J. Calderón, O. J. Guerra, L. G. Papageorgiou, and G. V. Reklaitis, "Disclosing water-energy-economics nexus in shale gas development," Applied Energy, vol. 225, pp. 710-731, 2018.

[10] R. F. Westwood, S. M. Toon, and N. J. Cassidy, "A sensitivity analysis of the effect of pumping parameters on hydraulic fracture networks and local stresses during shale gas operations," Fuel, vol. 203, no. 9, pp. 843-852, 2017.

[11] X. Wang, H. Ge, J. Wang, D. Wang, and H. Chen, "Evaluation of the micro-cracks in shale from the stress sensitivity of ultrasonic velocities," Rock Mechanics and Rock Engineering, vol. 49, no. 12, pp. 4929-4934, 2016.

[12] G. Cui, J. Liu, M. Wei, X. Feng, and D. Elsworth, "Evolution of permeability during the process of shale gas extraction," Journal of Natural Gas Science and Engineering, vol. 49, pp. 94-109, 2018.

[13] Z. Liu, B. Bai, Z. Zhang, J. Tang, S. Zeng, and X. Li, "Experimental study on the influence of slickwater on shale permeability," IOP Conference Series: Earth and Environmental Science, vol. 113, article 012225, 2018.

[14] L. Wang, S. Yang, Z. Meng et al., "Time-dependent shape factors for fractured reservoir simulation: effect of stress sensitivity in matrix system," Journal of Petroleum Science and Engineering, vol. 163, pp. 556-569, 2018.

[15] G. Cui, J. Liu, M. Wei, R. Shi, and D. Elsworth, "Why shale permeability changes under variable effective stresses: new insights," Fuel, vol. 213, pp. 55-71, 2018.

[16] Y. Liu, P. Yu, and Z. Ding, "Research on stress-sensitivity of fractured porous media," Journal of Petroleum Science and Engineering, vol. 171, pp. 879-889, 2018.

[17] Z. Wu, Y. Zuo, S. Wang, J. Sunwen, and L. Liu, "Experimental study on the stress sensitivity and influence factors of shale under varying stress," Shock and Vibration, vol. 2018, Article ID 3616942, 9 pages, 2018.

[18] R. Zhang, Z. Ning, F. Yang, H. Zhao, L. Du, and X. Zhou, "Experimental study on stress sensitivity of shale and analysis of influencing factors," Journal of Rock Mechanics and Engineering, vol. 34, no. S1, pp. 2617-2622, 2015.

[19] J. He, Y. Kang, L. You, X. Du, and Q. Cheng, "Effects of mineral composition and microstructures on stress sensitivity of 
argillaceous reservoirs," Natural Gas Geoscience, vol. 23, no. 1, pp. 129-134, 2012.

[20] B. Wang, Y. Qin, J. Shen, G. Wang, and Q. Zhang, "Influence of stress and formation water properties on velocity sensitivity of lignite reservoir using simulation experiment," Fuel, vol. 224, pp. 579-590, 2018.

[21] J. Zhao, L. Ren, C. Shen, and Y. Li, "Latest research progresses in network fracturing theories and technologies for shale gas reservoirs," Natural Gas Industry B, vol. 5, no. 5, pp. 533546, 2018.

[22] M. Pervukhina, B. Gurevich, P. Golodoniuc, and D. N. Dewhurst, "Parameterization of elastic stress sensitivity in shales," Geophysics, vol. 76, no. 3, pp. WA147-WA155, 2011.

[23] Z. Wentong, W. Qing, N. Zhengfu, Z. Rui, H. Liang, and C. Zhilin, "Relationship between the stress sensitivity and pore structure of shale," Journal of Natural Gas Science and Engineering, vol. 59, pp. 440-451, 2018.

[24] Y. Shen, H. Ge, M. Meng, Z. Jiang, and X. Yang, "Effect of water imbibition on shale permeability and its influence on gas production," Energy \& Fuels, vol. 31, no. 5, pp. 49734980, 2017.

[25] C. MacBeth, Y. HajNasser, K. Stephen, and A. Gardiner, "Exploring the effect of meso-scale shale beds on a reservoir's overall stress sensitivity to seismic waves," Geophysical Prospecting, vol. 59, no. 1, pp. 90-110, 2011.

[26] H. Gao, C. Wang, J. Cao, M. He, and L. Dou, "Quantitative study on the stress sensitivity of pores in tight sandstone reservoirs of Ordos basin using NMR technique," Journal of Petroleum Science and Engineering, vol. 172, pp. 401-410, 2019.

[27] Z. Gao, R. Huang, Z. Jiang et al., "Investigate the spontaneous imbibition characteristics of marine and continental shales and their controlling factors," in Agu Fall Meeting, Seattle, WA, USA, 2016.

[28] L. You, Q. Wang, Y. Kang, H. Liu, and C. Fang, "Effects of fracturing fluid infiltration on stress sensitivity of shale reservoirs," Oil and gas geology and recovery, vol. 21, no. 6, pp. 102-106, 2014.

[29] Y. Kang, C. Lin, L. You, Q. Wang, and Q. Chen, "Effect of oilbased drilling and completion fluid invasion on stress sensitivity of shale reservoirs," Natural Gas Industry, vol. 35, no. 6, pp. 64-69, 2015.

[30] Y. Kang, B. Yang, X. Li, J. Yang, L. You, and Q. Chen, “Quantitative characterization of micro forces in shale hydration and field applications," Petroleum Exploration and Development, vol. 44, no. 2, pp. 328-335, 2017.

[31] X. Liu, J. Xiong, and L. Liang, "Experimental study on hydration of hard and brittle shale in Longmaxi Formation," Journal of Southwest Petroleum University: Natural Science Edition, vol. 38, no. 3, pp. 178-186, 2016.

[32] R. M. Holt and M. I. Kolst $\varnothing$, "How does water near clay mineral surfaces influence the rock physics of shales?," Geophysical Prospecting, vol. 65, no. 6, pp. 1615-1629, 2017.

[33] B. Qian, J. Zhu, H. Yang et al., "Experiments on shale reservoirs plugs hydration," Petroleum Exploration and Development Online, vol. 44, no. 4, pp. 652-658, 2017.

[34] D. Davudov and R. G. Moghanloo, "Impact of pore compressibility and connectivity loss on shale permeability," International Journal of Coal Geology, vol. 187, pp. 98113, 2018.

[35] F. Wang, X. Li, G. Couples et al., "Stress arching effect on stress sensitivity of permeability and gas well production in Sulige gas field," Journal of Petroleum Science \& Engineering, vol. 125, pp. 234-246, 2015.

[36] J. Sun, Z. Yang, X. Liu, R. Yu, and C. Feng, "Study of permeability stress-sensitivity characteristics and its evaluation method of ultra-low permeability reservoir using different types of fluid media," Chinese Journal of Rock Mechanics \& Engineering, vol. 32, no. 2, pp. 324-332, 2013.

[37] P. Guo, J. Zhang, J. Du, Y. Xu, and G. Wu, "Study on stress sensitivity of gas reservoir cores by two experimental methods," Journal of Southwest Petroleum University, vol. 29, no. 2, pp. 7-9, 2007.

[38] Z. Yu, W. Xiong, S. Gao, and J. Liu, "Stress sensitivity of tight reservoirs and its impact on oilfield development," Journal of Petroleum, vol. 28, no. 4, pp. 95-98, 2007.

[39] J. R. Pedrosa, "Pressure transient response in stress-sensitive formations," in Society of Petroleum Engineers, p. 15115, Oakland, CA, USA, 1986.

[40] C. Li, "Evaluation method of stress sensitivity of reservoir rocks," Petroleum Geology \& Oilfield Development in Daqing, vol. 1, pp. 40-42, 2006.

[41] R. Zhang, Z. Ning, F. Yang, and H. Zhao, "Shale stress sensitivity experiment and mechanism," Journal of Petroleum, vol. 36, no. 2, pp. 224-231, 2015.

[42] Y. Zhuang, X. Liu, H. Xiong, and L. Liang, "Microscopic mechanism of clay minerals on reservoir damage during steam injection in unconsolidated sandstone," Energy \& Fuels, vol. 32, no. 4, pp. 4671-4681, 2018. 

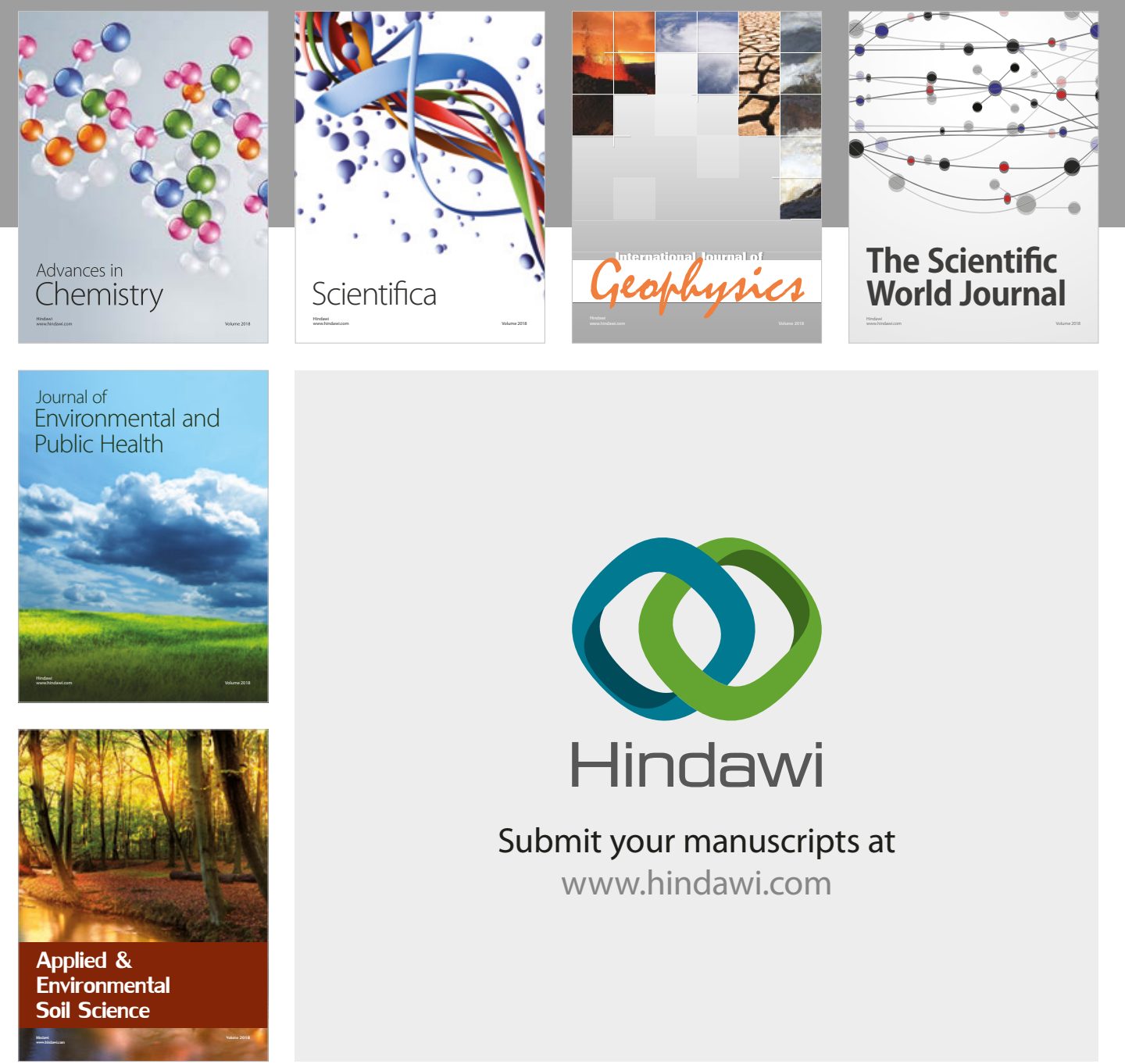

The Scientific

\section{World Journal}
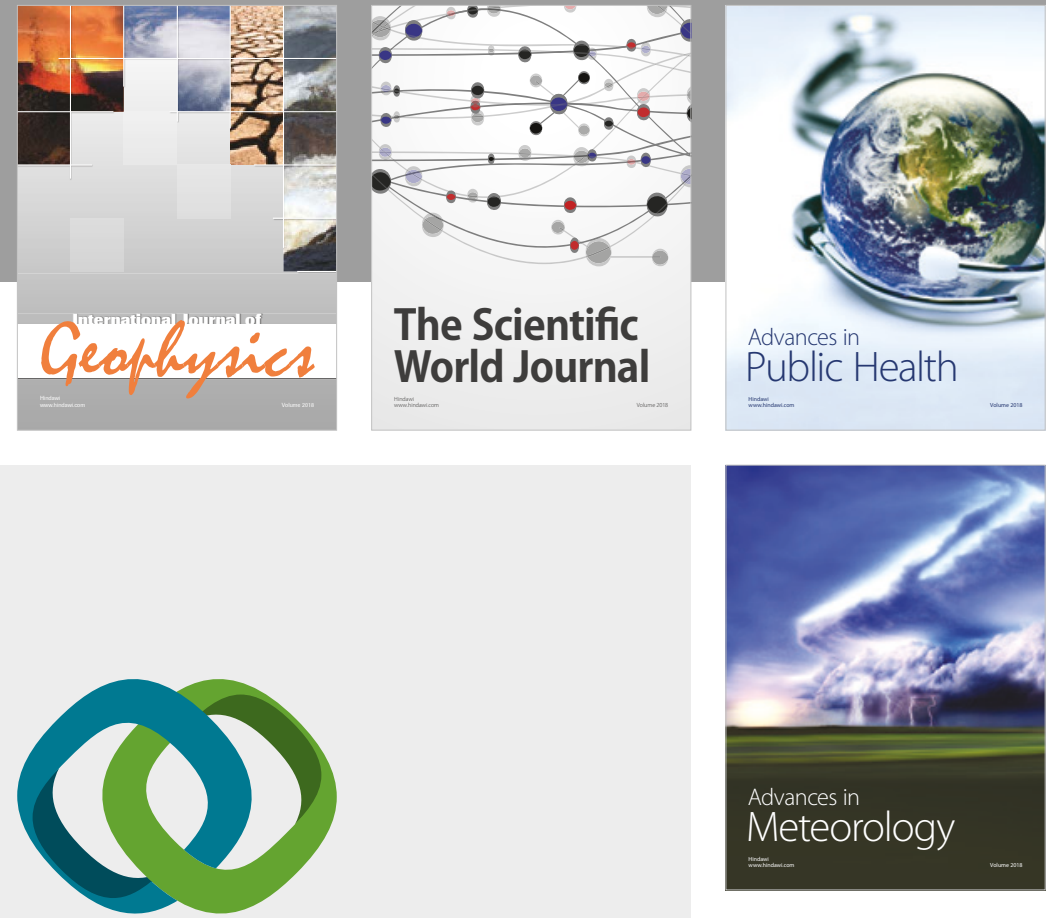

Advan

Public Health

\section{Hindawi}

Submit your manuscripts at

www.hindawi.com
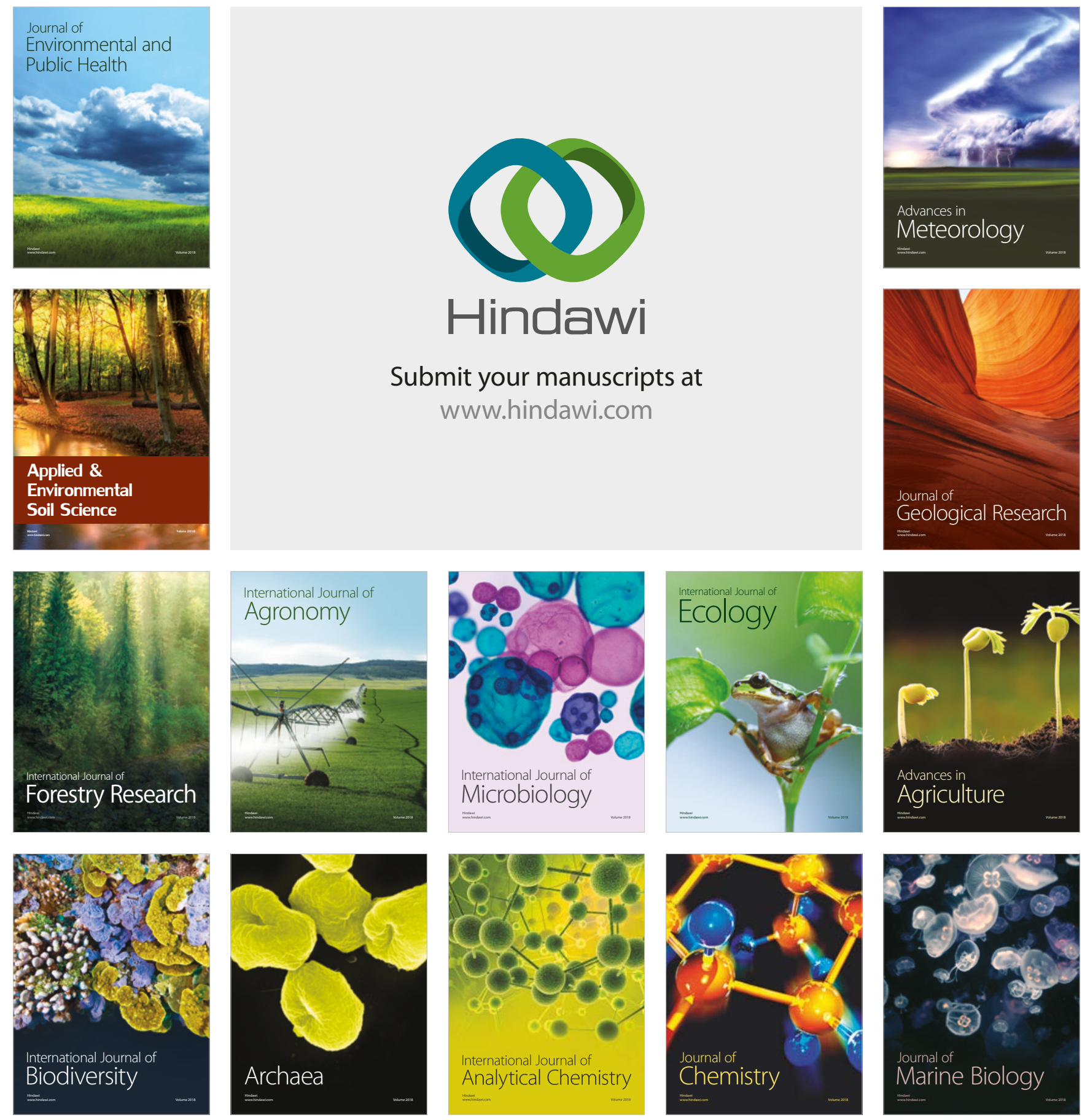